\begin{abstract}
Drawing on Deleuze's 'Postscript on Control Societies', our initial focus in this article will be on the role of institutions within societies of control, an analysis which brings Deleuze into the orbit of Ervin Goffman's famous ethnographic work on total institutions. This cross-comparative analysis of Deleuze and Goffman (also montaged with Foucault's important work on disciplinary institutions) will allow us to show how institutions of control function by sequencing dividuals across institutional domains in a continual process of totalization. Inspired by James Williams's recent work on the 'process philosophy of signs', we then argue that a critique of totalizing institutions can be positively articulated as a process oriented challenge to algorithmic technologies and as a counter-sequencing of institutional control. We conclude with some reflections upon the emergent modes of resistance that challenge both institutional and technological control and we will proffer criteria for assessing such practices in relation to the two-sided nature of critique they enact, both processual and counter-sequential.
\end{abstract}

Key words: societies of control, totalizing institutions, critique, resistance, Deleuze, Goffman, Foucault.

\title{
Authors
}

Iain MacKenzie is Co-Director of the Centre for Critical Thought, School of Politics and International Relations, University of Kent, Canterbury, CT2 7NX, Telephone: +441227824507, Email: i.mackenzie@kent.ac.uk

Robert Porter is Director of The Centre For Media Research, Ulster University, Northern Ireland BT37 0QB, United Kingdom, Telephone +442870124974, Email: r.porter@ulster.ac.uk 
As Michael Hardt notes, it is clear that Deleuze's (1995) famous 'Postscript on Control Societies' says 'very little about the society of control' (Hardt, 1998, p. 139). Taking up the challenge of developing Deleuze's elliptical remarks, Hardt frames his task in two ways: in relation to the 'withering of civil society' and 'the passage from imperialism...to Empire, today's world order' (Hardt, 1998, p. 138). More recently, others looking to fill in Deleuze's sketch of control society have taken a different path. Inspired by the rise of social media and the use of increasingly sophisticated forms of computation at all levels of politics, economics and society they have focused on the technological developments that enable control to function evermore smoothly and pervasively: a new age of 'total planetary computation'? (Greenfield 2018; Bratton, 2016; Galloway, 2016; Rouvroy, 2012) Both approaches have contributed greatly to our understanding of control societies, at the global and the technological levels. That said, there remains a problem. For Deleuze, the emergence of control society is a process that begins with the crisis of disciplinary institutions. Indeed, Hardt puts it well when he notes: 'the walls of the institutions are breaking down in such a way that their disciplinary logics do not become ineffective but are rather generalized in fluid forms across the social field' (Hardt, 1998, p. 139). However, there has been no sustained interrogation of how exactly these new institutional formations function. The walls may be 'breaking down' but it is not clear how the institutions operate 'across the social field' and, therefore, how the rise of new institutional forms supports, and is supported by, the technological apparatuses of control. As a consequence, attempts to consider the relationship between control, critique and resistance have been hampered by an over-emphasis on general global 
dynamics and on technological innovations, at the expense of the insights that can be garnered from detailed analyses of the institutions themselves.

In this article we will provide a framework for these analyses by asking three interrelated questions. Firstly, how do the institutions of control societies function? Answering this question will require the development of an institutional analysis that complements Deleuze's (1995) brief but provocative characterization of societies of control. There are two aspects to developing this analysis: a) charting the well-known distinction Deleuze draws between disciplinary and control societies (in particular the shift from regimes of individuation to those of dividuation) and then, b) introducing a perhaps more surprising comparison between societies of control and Goffman's (1961) ethnographic work on total institutions. This latter aspect will allow us to develop Hardt's insight by assessing the shift from disciplinary to control institutions as one best described as a breakdown of the total function of the former to the totalizing function of the latter. Bringing the two aspects together we will argue that institutions of control function by sequencing dividuals across institutional domains in a process of totalization. This institutional analysis complements the more technologically oriented analyses that Deleuze's characterization of control has engendered (partly as a result of ambiguities in his own discussion, as we will see below). Many accounts of control societies tend toward a partial, technological analysis of how control functions and this has an important bearing on the other two questions we want to pose.

Second, what is the status of critique in control societies? While the idea of critique as a practice of establishing the legitimate limits of knowledge emerged within sovereign societies and was then reframed as practices that transgressed 
those limits in disciplinary societies, it is by no means clear what, if any, new practice of critique is appropriate for societies of control. Indeed, it has become increasingly commonplace to argue that critique is no longer relevant. It is thought by some contemporary theorists of a neo-Heideggerian hue to be 'exhausted' such that it should give way to matters of concern (for example, Latour, 2004; Harman, 2011) whereas those looking to revive the communist idea argue that critique is irretrievably implicated in the sordid game of 'parliamentarianism' such that it should be replaced by a reinvigorated sense of political commitment (for example, Badiou and Žižek, 2009). On the contrary, we will argue that a critique of control society from within its own logic of constitution - that is, an immanent critique can be positively articulated both as a process oriented challenge to algorithmic technologies and as a counter-sequencing of the totalizing function of institutional control.

The third question we will address is this: does the possibility of a critique of control infer modes of resistance to both its institutional and technological forms? At the end of his essay on control societies, Deleuze ponders whether or not trade unions still have a role in the struggle against disciplines or 'will they give way to new forms of resistance against control societies?' (Deleuze, 1995, p. 182). He suggests that this is a task 'for young people'; almost three decades later have these people found modes of resistance against the 'snake's coils'? We will conclude with some reflections upon the emergent modes of resistance that challenge both institutional and technological control. Answers to these three questions must begin with a close reading of Deleuze's 'Postscript'. 
Deleuze's essay is split into three sections: 'History', 'Logic', and 'Program', with the middle section afforded the most space. In the 'History' section, Deleuze gives one of the most succinct and yet instructive accounts available of how Foucault understood the emergence of disciplinary societies; how, once established, disciplinary institutions function; and, how they were already fading out of existence in the aftermath of the Second World War. According to Deleuze, it was clear by the beginning of the twentieth century that there had been a 'transformation from one kind of society to another' (Deleuze, 1995, p. 178). 'Major sites of confinement' that operate by segmenting individual lives and populations into designated roles and functions characterize this new disciplinary model of society. This segmentation is most obvious as one moves from one site to another: 'you're not at home, you know', 'you're not at school, you know' (Deleuze, 1995, p. 177). But, as Deleuze acknowledges, Foucault - the great analyst of disciplinary societies - already knew, as he was writing Discipline and Punish, that disciplinary institutions were breaking down and new forms of governance were taking hold. Deleuze adapts an idea from William Burroughs when he labels the emergent post-disciplinary dispositif; control (Deleuze, 1995, p. 178).

The section titled 'Logic' has three component parts; it deals first with the nature of institutions and their relation to each other within societies of control; it then moves on to a discussion of how this affects individuals at the personal and collective levels; before ending with a discussion of the machines that correspond to control (all the while sharpening the contrast between discipline and control). We will take each in turn. Where disciplinary institutions were characterized by 'independent variables', control societies operate by way of 'inseparable variations' (Deleuze, 1995, p. 178). In a justly famous distinction, he argues that 
disciplinary confinement molded individuals according to roles and functions whereas controls are defined by modulations that traverse both the social field and the life-course of individuals. He gives two main examples; the shift from factories to businesses and the shift from schools as sites of discipline to the idea of continuing education as a mode of control. It is worth quoting what he says about the latter:

Even the state education system has been looking at the principle of 'getting paid for results'; in fact, just as businesses are replacing factories, school is being replaced by continuing education and exams by continuous assessment. It is the surest way of turning education into a business (Deleuze, 1995, p. 179).

On the one hand, we can say that this is a prescient remark borne out by the recent history of state education at all levels. On the other hand, we might say that Deleuze didn't entirely foresee that the same logic was beginning to turn businesses, and other institutions, into education systems.

Turning to forms of political subjectivity engendered by control, Deleuze contrasts the processes of individuation operative within disciplinary institutions with those processes of dividuation that signal control. 'We are no longer dealing with a duality of mass and individual' he says, rather 'individuals become dividuals and masses become samples, data, markets or banks' (Deleuze, 1995, p. 180). What is a dividual? A dividual is a bundle of elements held together in variation rather than in reference to a unitary subject. Where disciplinary institutions segmented the life-course of individuals into separate subjective roles and functions, control modulates elements of subjectivity across the entire social field. Where disciplinary societies required institutions to normalize behaviour in 
subject positions, control societies optimize dividuated behaviours without norm (Tarizzo, 2013).

How are such processes of dividuation made operative as control? Deleuze turns to the machines that correspond to this form of society - information technologies and computers - adding that this technological development is deeply rooted in a mutation of capitalism' (Deleuze, 1995, p. 180), moving from proprietorial forms of production to 'metaproduction' such that 'marketing is now the instrument of social control' that 'produces the arrogant breed who are our masters' (Deleuze, 1995, p. 181). Although Deleuze is clear that this correspondence should not be taken to indicate any hint of a technological determinist reading of the base-superstructure relation (Deleuze, 1995, p. 180), it is evident that this section places an emphasis upon the technological forms through which control functions, a feature that is then further cemented in the last section.

The last section, 'Program', has a dual function that plays on two senses of the word. It begins with a summary remark regarding the ways in which contemporary societies embed programmable mechanisms of control within information and computational technologies. But it also contains the seeds of a (political or revolutionary) program to challenge control. In relation to the former, Deleuze returns to the brief examples of how disciplinary institutions are breaking down and being supplanted by mechanisms of control located in the continual modulation of dividuals. In relation to the latter, he says that we must find both 'the basic socio-technological principles of control mechanisms as their age dawns' (Deleuze, 1995, p. 182) and in so doing see if we can glimpse the outlines of future forms of resistance to control. 
However, by now we may sense a slight but important shift in Deleuze's account. While the Postscript begins with claims about the general breakdown of disciplinary institutions and their transformation into new institutions of control there is, by the end of the essay, a tendency to discuss the transition from discipline to control as one that leaves institutions behind altogether, in favour of technological expressions of this newly emergent society. Perhaps it is unsurprising, therefore, that much of the work that has drawn inspiration from this essay has focused on the technological aspects of control societies rather than on its institutional features. Galloway provides a striking case in point: 'the society of control is characterized not by the power of the institutions of modernity, or pre-modernity, the army, the prison, the university, the church, but instead by what he [Deleuze] called the ultra-rapid forms of free-floating control that are inherent in distributed networks' (Galloway, 2006, pp. 318-9). Despite the slippage in Deleuze's presentation, however, and the attendant focus within the secondary commentary on his essay on technological forms of control, we suggest that it remains crucial to understand the transition from discipline to control as a process in which the institutions are transformed, rather than treating it as the emergence of a de-institutionalized social formation. The aim is not to criticize technological accounts of control - in fact, they are becoming especially pertinent as the everyday lifeworld we inhabit is increasingly governed by computational or algorithmic logics - but to complement those analyses with an awareness of the how institutions function in control societies. That said, we shall argue that focusing only on technological advances as indicators of control does jeopardize the practical element of Deleuze's 'Program': what are we to do in relation to the emergence of these new forms of governance, if we want to critique them and then 
to resist? This leads us to consider the following question: what is the role of institutions in control societies?

\section{Institutions of Control}

While it is now widely understood that disciplinary institutions segment individuals and populations into a series of independent subject positions, control institutions function by separating the components of individuality in ways that tend toward the dispersal of these dividuals across the whole social field, often in conflictual and contradictory ways. The population in control societies is no longer a mass (of individuals) but a trajectory of dividuation tending toward total absorption with the technological mechanisms of control. In this sense, the institutions of control serve to totalize the dividuated elements of previously disciplined subjects without harmonizing these in any one subject position at any given time or across a life-course thereby aiding in their technological dispersion through the machines that correspond to control.

As it stands, though, this is merely a slight corrective to a tendency within Deleuze's essay in which he shifts subtly from a claim about the transformation of institutions to one about the breakdown and implied disappearance of institutions. However, we can give it more nuance if we explore the ways in which the totalizing institutions of control societies can be compared to the total institutions analyzed by Goffman.

When Goffman published his essay 'On the Characteristics of Total Institutions' we might say that the owl of Minerva was indeed taking flight and social theorists were able to grasp the significance of Victorian institutional formations as they were beginning to fade. Nonetheless, and as Deleuze insists in 
regard to Foucault's account of disciplinary institutions, they continue to hold sway in many respects (just as there are many elements of sovereign societies that still pervade institutional life) and in their gradual transformation we can see not only how these institutions have shaped the past but also what may be emerging as new institutions in the present. Goffman's idea of the total institution is useful in this regard, in two respects: firstly, by virtue of differentiating total from disciplinary and totalizing institutions; second, by virtue of the extent to which he anticipated the emergence of totalizing institutions.

For Goffman, total institutions come in different forms - psychiatric institutions, monasteries and army camps, for example - but they all share certain basic features oriented by the management of a person's 'sleep, play and work' under a single authority. As Goffman puts it, the 'central feature of total institutions can be described as the breakdown of the barriers ordinarily separating these three spheres of life' (sleep, play and work) such that 'all aspects of life are conducted in the same place and under the same single authority' (Goffman, 1961, p. 17). In a manner reminiscent of Foucault's account of disciplinary institutions, Goffman goes on to detail how all total institutions also involve placing people within batches that are 'treated alike and required to do the same thing together' and that members of a total institution lead regularized life governed by schedules, 'the whole sequence of activities being imposed from above by a system of explicit formal rulings and a body of officials' (Goffman, 1961, p. 17).

That said, a further general feature of total institutions begins to show the difference with Foucault. For Goffman, total institutions are all oriented by a single plan at odds with everyday activity that, in contrast, operates 'without an overall 
rational plan' (Goffman, 1961, p. 17). Where Goffman still presumes a division between normal civil society and the total institutions that hybridize aspects of that normal existence (Goffman, 1961, pp. 17-18), Foucault understands the diagrammatic nature and function of disciplinary institutions within all aspects of life (Foucault, 1977, pp. 200-209). Both understand the corrective nature of institutions but Goffman tends to see this correction as one in which the presumption of a correct form of life resides, whereas Foucault grasps that correction is the process of norm creation in the first place. In this sense, it is clear that Goffman's total institutions are not Foucault's disciplinary ones, even though there is a sense in which both thinkers are grappling with the fading of these institutions in a post-WWII setting. But to what extent is the idea of total institution useful in establishing what is happening with the breakdown of disciplinary institutions if they are not, after all, the same thing?

Perhaps paradoxically, while Foucault's analysis of the diagrammatic features of disciplinary institutions avoids a problematic presumption of relatively normal 'civil society', it does tend toward fixing the logic of discipline into the institutional apparatuses in a manner that doesn't usefully capture the dynamism of the transformations at work. Intriguingly, Goffman's analysis of total institutions from the very start presents a fluid conception of how these institutions permeate civil society. 'For example', he says, 'our large commercial, industrial and educational establishments are increasingly providing cafeterias and free-time recreation for their members' (Goffman, 1961, p. 17). Where he remains naive is in thinking that 'special care is taken to ensure that the ordinary line of authority does not extend to [such facilities]' (Goffman, 1961, p. 17). Nonetheless, this astute awareness of how institutions are becoming increasingly 
'permeable' (Goffman, 1961, p. 113) and how such permeability can have variable consequences for inmates and staff alike (and the population at large) brings his analysis close to the Foucauldian idea that everyone is captured in an institution while nonetheless retaining a plural understanding of the processes of capture. We may consider the totalizing institutions of control society in terms of the transformation of the diagrammatic feature of disciplinary institutions instilled with an awareness of the institutional permeability that comes from Goffman, minus his optimistic belief in relatively free non-rational logics of civil society but instead with a nuanced understanding of these disaggregated and increasingly technical forms of authority. The shift from the designation total to 'totalizing' indicates these dynamic institutional features.

Adapting Deleuze's succinct characterization of disciplinary instruction we might say that the linguistic form of control institutions is this: 'you are still a child, you know', 'you are still a patient, you know', 'you are still a learner, you know', 'you are still a consumer, you know', etc. It is a striking feature of life within contemporary institutions of control that one is always, to some degree, a child, a school pupil, an apprentice, a university student, a worker, a consumer, a parent, a patient, a prisoner, a free person etc. but one is never merely one of these things at any one time (a disciplined subject of an institution). However, it is not enough to say that institutional life is controlled through the maintenance of all of these dividuated features, as this would imply that life in one totalizing institution would always be the same as life in another. In fact, it is important to note initially, before we can formalize this in the next section, that the dividuated components operative within institutional formations of control are always sequenced in particular ways (though changeable, conflictual and even contradictory). Exactly 
how these dividuated components are sequenced will not only vary between different totalizing institutions but within each institution depending on other factors at play in the everyday rough and tumble of institutional life.

These latter features of totalizing institutions can be elaborated via Goffman's own theoretical framing of the dramatic qualities of everyday life. In The Presentation of Self in Everyday Life, Goffman (1990) accounts for the theatrical elements of face-to-face interactions. In such interactions, individuals act in specific ways in specific settings, in much the same way that actors perform a role on the stage. Drawing out this comparison, he claims, enables the sociologist to focus on the way individuals present themselves to each other, the scene in which such presentations occur and the dynamics of interaction conditioned by both role and setting. While malleable in everyday life, these roles and settings are relatively fixed by total institutions, a process he refers to as 'mortification' - the everyday ability to own a role, present oneself in a certain way, is replaced by 'role dispossession' (Goffman, 1961, p. 24). The inmate, for example, 'finds certain roles are lost to him by virtue of the barrier that separates him from the outside world' and it is intriguing that he considers the entrance into total institutions as a form of 'coding', where the individual is 'coded into an object that can be fed into the administrative machinery of the establishment, to be worked on smoothly by routine operations' (Goffman, 1961, p. 26). For all that this prefigures the technological dimension of control outlined by Deleuze, there is still, in Goffman, a sense that 'civil life, the sequential scheduling of the individual's roles, both in the life cycle and in the repeated daily round, ensures that no one role he plays will block his performance and ties in another' (Goffman, 1961, p. 24). Ultimately, indeed, Goffman's understanding of the theatrical implies not only a sense of 
normal role functioning but also a backstage; that area where we can let our social roles slip and simply 'be ourselves'. But if, following Foucault and Deleuze, there is no such civil life that stands in contrast to institutional life nor a backstage that serves as a normative benchmark for analyses then, in fact, we are having to occupy several stages all at once, perform several roles all at once, construct several scenes all at once, in all aspects of our lives, with no backstage as a site of retreat. This is the condition of life in totalizing institutions of control. It can be clarified once more with reference to disciplinary institutions.

Where disciplinary institutions operate through the making of subjects, control societies totalize dividuals without the formation of a subjective centre. Every aspect of one's life is put into continuous variation with every other such that we are always performing multiple roles at the same time. However, it is important to recall that we are not performing multiple selves, rather we are stretched across the institutional domain as dividuated actors who are nothing but the roles we play and we have to play all of these roles all the time in any given institutional setting, albeit in a particularly sequenced manner. Where Goffman (1990) thought we could switch roles in civil life with relative ease because we were able, in private life backstage, to let the mask slip, and Foucault (1977) thought that disciplinary roles were forged on docile bodies to turn them into subjects of the institution, in control societies there are roles without subjects backstage or on stage. Instead, there are only collections of roles (often experienced as contradictory or, at least, in tension) dispersed across the stage and across several stages all at once.

Before moving on to the following section it is worth summarizing the claims so far. Deleuze's 'Postscript' implicitly presents two versions of the 
emergence of societies of control; the first emphasizes the changing nature of institutional forms, the second emphasizes processes of de-institutionalization and increasing technological forms of governance. While the latter has been picked up more extensively in the literature, the changing nature of institutions has remained under theorized. Drawing together the dynamic and dramatic approach to total institutions developed by Goffman and the diagrammatic features of subject formation in Foucault's account of disciplinary institutions enables a better understanding of what is at stake in the institutions of control society. In short, these institutions function by totalizing dividuated components of subjectivity in malleable sequences that are dispersed between and within these institutional forms.

\section{Critique in Control Societies}

What is the status of critique in control societies? The question is framed in this way because it is not clear what role, if any, critical theory, broadly understood, can play in control societies. It is a problem that Rouvroy has expressed very clearly (although she refers to the role of critique after the 'computational turn'):

I wonder if it is still possible to practice critical thinking after a computational turn, which despite its pretence to 'objectivity', appears as a turning point away from the ambitions of modern rationality anchored in empirical experiment and deductive - causal - logic and, despite its promises of personalization and better taking into consideration of individual merits, needs, abilities, preferences, does not address individuals through their reflexive capabilities or through 
their inscription within collective structures, but merely through their 'profiles' (Rouvroy, 2012, p. 2).

Moreover, she argues that there are three key features of life under the 'computational turn' that make critique difficult to practice. First, the background of 'real life' (no matter how constructed we might think this is) is becoming 'indistinct' (Rouvroy, 2012, p. 2). Secondly, the modern framework of judicial and scientific testing through experiment has been superseded by 'the real time, preemptive production of algorithmic reality' (Rouvroy, 2012, p. 2). Thirdly, what she calls 'algorithmic governmentality' is a regulative form without subject, such that it does not allow for or enable the reflexivity necessary for critique (Rouvroy, 2012, p. 2). This is a delimitation of the problem of critique today with which we broadly agree: it is no longer possible to rely upon the reflexive capacities of subjects, especially if these are deemed to be part of our innate cognitive apparatus, in order to ground critique in societies of control. We will, however, suggest a broader framing of this problem that in turn will slightly alter her account of the status of critique today: as we will argue below, we are less convinced than Rouvroy of the potential that remains within transgressive forms of critique in a post-disciplinary context of control.

From the perspective of current theoretical debates, we can see that it is indeed the case that there is an increasing consensus that the age of critique has come to an end. Certainly, it remains the case that the idea of critique as a practice of establishing the limits of legitimate forms of knowledge available to a reflexive subject that emerged within sovereign societies is still an important strand of those inheritors of Kant committed to the communicative turn (notably, second generation Critical Theory, hermeneutics and varieties of second wave feminism). 
Moreover, for those suspicious of the exclusionary and disciplinary consequences of such critical practices, it became important to reframe the idea of critique as a practice that transgresses those subjective limits by exposing their historical and cultural contingency (notably, third-wave feminism, post-Marxism and poststructuralism). Critique as a practice of stepping beyond the limits of possible knowledge, for some, came to replace the idea that critique should establish the limits of legitimate knowledge. To the extent that we still see the pernicious effects of disciplinary institutions the world over, such practices of transgressive critique still hold sway. However, if it is the case that we increasingly live under regimes of 'algorithmic governmentality' or, what we would call, an emergent postdisciplinary society of control then it is by no means clear what, if any, new practice of critique is appropriate for this emerging new epoch. In the face of this uncertainty, it is perhaps not surprising to note that the apparently radical cutting-edge of contemporary philosophical inquiry has sought to leave behind the idea of philosophical and practical critique altogether. It has become increasingly commonplace to argue that critique is either exhausted such that it should be replaced by a deeper appreciation of matters of concern (Latour, 2004; Harman, 2011) or, that the tendency of parliamentary-capitalism to recuperate critical positions means that it should be replaced by a revitalized politics of commitment (Badiou and Žižek, 2009). However, in line with Rouvroy, we take it that the status of critique in control societies can be positively reframed and that it is necessary to do so if we are to ward off the dangers of a conservative embrace of that which simply concerns us most, or a dogmatic position of commitment in the name of a subject of truth that can simply break open and away from the democratic marshalling of fixed and unchallenged opinions. In this sense, we claim 
that critique has a history. Not just that it must mobilize historical material to ward off a-historical tendencies, in the manner of historical materialism or genealogy for example, but that the very idea and practice of critique must adapt as social formations evolve and change. But what remains of critique if there is no recourse to the reflexive subject, its communicative variant or the transgression of limits set by both?

Rouvroy presents a compelling answer: 'what has to be preserved as antecedent to both the subject and sociality, as excess of the world over algorithmic reality, is "the common", the "in-between", this space of common appearance in which we are mutually addressed to each other' (Rouvroy, 2012, p. 13). It is a space that she argues can be constructed in many different 'heterotopic spatio-temporal spaces interrupting digital and capitalist flows - such as the judicial, theatrical, literary, laboratory scenes' (Rouvroy, 2012, p. 14). It is notable, though, that she argues for a particular role of the judicial in this regard. She claims that law retains the possibility for constructing legal personalities which can express 'individual or collective agencies or potencies' such that norms can be made explicit and contestable by newly constituted subjects-in-common that can give 'an account of themselves' against the neutralizing tendencies of algorithmic governmentality (Rouvroy, 2012, p. 15). Indeed, there is an echo of Rouvroy's appeal to critique as the judicial practice of giving voice to 'the common' in the work of Raunig (2016); another penetrating critic of control society. For Raunig, 'law is not necessarily always only a preserving power, handmaid of a force long since constituted, tool of established institutions' it can become, in its jurisprudential form, a means by which we can achieve a 'new actuality with each new judgement' (Raunig, 2016, p. 171). He goes so far as to name this form of law, 
'dividual law'; a form of judicial practice that is 'not based on individuals and their property but rather on the singularity of manifold ecologies beyond property and individualization' (Raunig, 2016, p. 175).

Compelling as both these attempts at the judicial reframing of the idea of critique may be, they nonetheless tend toward an idea of critique that is unlikely to have real critical purchase because they remain committed to the link between critique and (judicial) limitation, even in the name of its transgression. This is the case because neither goes far enough with either the potential grounds of a critique of algorithmic governmentality or with their analyses of how the institutions of control society function. While we have gone some way towards the latter dimension in the previous section, in the remainder of this section we will clarify what we mean by the grounds of a critique of control in such a way that it will enable us to formalize the nature of the totalization of dividuals that defines institutions of control. Once clarified we can then summarize the task of critique in control societies such that we will offer, in the concluding section, certain tentative criteria for assessing whether or not practices of resistance may, to some extent at least, be adequately formulated to unravel 'the snakes' coils'.

Two questions are useful in setting out the task of critique in contemporary societies of control: what is an algorithm? And how do totalizing institutions sustain algorithmic functioning? Considering the first, an algorithm is a selfcontained step-by-step set of operations to be performed. There are three key elements to this definition that are important for our discussion. First, while a human may perform the algorithmic task, increasingly it is a task that is outsourced to computers. Rouvroy puts it succinctly when she says that algorithmically produced knowledge is no longer produced by humans about the 
world, rather it is 'produced from the digital world' (Rouvroy, 2012, p. 4). Secondly, an algorithm is a process, but importantly it is a finite and contained process. In this sense, it is correct to talk of algorithms as 'IF...THEN...functions', where IF specifies the conditions of the operations and THEN specifies the consequences of the operation. Thirdly, that which is operated upon can be referred to as data, information, code and so on but we follow Lazzarato's (2014) treatment of these as signs. The sign can in principle take any 'computable' form: it may be a number, but it could just as legitimately be a visual symbol, a bodily gesture, a click on a keyboard, a smell; even a user's attentiveness or not to parts of a screen (Bueno, 2017). In sum, therefore, our initial definition of an algorithm can be parsed as follows: an algorithm is a finite process of establishing consequences from conditions by virtue of operations that act upon signs. When understood in this way, it is clear that algorithmic realities present a fundamental challenge to the idea of critique.

What these clarifications also highlight, however, is a prima facie case to turn to a process philosophy of signs in order to interrogate what is required of a critique of control societies, at the level of the algorithm. If we understand algorithms as fixed and limited processes then it makes sense to approach the critique of how they operate from within the conditions of their own production; that is, as processes that operate upon signs. Williams (2016) has outlined just such a process philosophy, albeit with different intent. In this work, Williams has constructed what he describes as an 'ontologically modest' process philosophy, one that does not look to establish the metaphysical status of processes but rather employs process philosophy in the service of a critical engagement with the world of signs. That said, it is, in our view, precisely this ontological modesty that enables 
Williams to provide a formal and practically rigorous critique of the ways in which signs are manipulated in algorithms.

According to Williams, the formal qualities of the sign are threefold: a) every sign is a selected set (Williams, 2016, p. 6); b) each set has at least one diagram that expresses the relations in and around the set (Williams, 2016, p. 6); c) each set is 'open to many diagrams that are not unique' such that each sign is open to revaluation (Williams, 2016, p. 7). While Williams then embarks upon a series of debates about the nature of the sign that range across biology and semiology, amongst other domains, we see the means whereby we can construct an approach to critique appropriate to the current dominant use of algorithms in social, economic and political life. As signs are manipulated through IF...THEN... functions so the set of the sign is fixed according to one diagram in order for it to serve as both condition and, in the case of another sign, consequence, with no consideration therefore to its possible revaluation. In simple terms, the algorithm fixes meaning but process philosophy establishes that every sign is in principle connected to every other sign such that one can always find a meaningful point from which to critique the algorithmic function itself. Processes even when considered in an ontologically modest fashion, are more fundamental than algorithms and, in that sense, will always exceed the algorithmic function because the processual connections between the component parts of the sign are in principle infinite. As Williams puts it: 'the process sign allows for layers of process by including signs within others...The main threat to this process definition comes from boundaries imposed on the sign as process, where the sign is given as static or limited' (Williams, 2016, p. 11). Algorithms, for all of their apparent fluidity and flow, are ultimately limited to the extent that they must presume particular 
significations within the sign in order for the bounded function to operate. The excess of potential expressed by a fully-fledged process philosophy of the sign, therefore, provides the immanent ground of a critique of algorithmic governmentality; immanent because it is internal to the logic that sustains the algorithm itself. In the terms that we prefer, process philosophy offers an immanent critique of the technological operators that modulate codes of control. While it is the processual nature of signs that enables algorithms to function, it is also this nature that enables their critique: 'as critical and creative, signs take on a function of alarm and innovation in conjunction with other claims to knowledge and to truth' (Williams, 2016, p. 172).

In itself, though, this processual critique of the algorithm is not enough to unravel control. In this respect, we agree broadly with Neyland and Möllers (2017) who challenge the idea that algorithms have an intrinsic power and agency such that their critique would be sufficient to challenge that power. Indeed, a similar point is made by Bueno in his work on the attention economy: 'a critique of the attention economy cannot remain at the level of the examination of the cybernetic machines that transform the productive process...but must move towards the analysis of the power diagram that produces and makes use of these new technologies' (Bueno, 2017, p. 135). What is needed, according to Neyland and Möllers (2017), is an appreciation of the 'situated character' of algorithmic systems; according to Bueno, a critique of the machinic dimension of cognitive capitalism must be matched with a critique of social subjection contained within the 'power diagram' with which the machinic is in a relationship of mutual imbrication; and, according to Williams (2016), we should focus on the 
diagrammatic relations of intensity that can be revaluated and contested in the political sign.

We are proposing that the 'totalizing institution' is the diagram (in Foucault's sense) of the institutional form that distributes dividuals in particular but malleable sequences that must be exposed and critiqued every bit as much as the functions of 'algorithmic governmentality' if we are to enact an immanent critique of societies of control. The key to understanding this institutional component of the critique of control societies resides in what we have called the sequential ordering of the dividuals of totalizing institutions: this means that the dominant aspect of the dividuated subject organizes the diagram of its role as a sign but this sign, in control societies, does not exclude but rather includes other elements in particular ways. The role of totalizing institutions, therefore, is to sustain particular distributions, particular and changeable diagrams, of these sequenced modulations in line with algorithmic functioning. They do this by sequencing dividuations in the first instance but also by retaining a certain, apparently open-ended but actually limited (hence totalizing but never total), series of components which then enables the functioning of the algorithms across different modulations of totalizing institutions.

While these algorithmic functions are now well known, and can be critiqued at the level of the potentially infinite process of signification they constrain, they can also be critiqued through a process we would call countersequencing. Counter-sequencing is the activity of reordering the power diagram of the totalizing institution in ways that destabilize its functioning. That said, it would be unwise to assume in advance that counter-sequencing must result in some kind of 'positive' ethico-political outcome. The aim, instead, is to understand 
the critical potential of counter-sequencing first and then to engage in, what Williams calls, the revaluation of that critique with more 'local', that is 'pragmatic', concerns at the forefront of such revaluations. At which point, the grounds of critique become the very stuff of the politics of totalizing institutions. Moreover, to the extent that the critique of totalizing institutions can be understood in this way we would claim that Rouvroy's (2012) and (less-so) Raunig's (2016) tendency toward a hopeful redeployment of the jurisprudential domain in the name of 'the in-between' or 'the common' is a matter of political dispute rather than the grounds for a critique of algorithmic governmentality or societies of control per se.

\section{Conclusion: On Resistance}

Having clarified what we understand as the grounds of critique in control societies, are we any nearer to the political task of deciding between alternative forms of resistance in order to unravel the snake's coils? If there is merit in our presentation of the totalizing institution as a key feature of the operation of control then the criteria for practices that resist control are to be found in both the process-oriented critique of the algorithm and the counter-sequencing of dividuals within institutions as part of the same practice.

The risk of recuperation within systems and institutions of control is everpresent if the focus is only on one side or the other of the technological and institutional domains. A focus on the process-oriented critique of algorithms alone may tend toward the valorization of certain networked practices that ultimately play into the hands of algorithmic forms of governmentality. At its most superficial level, this is clear in Facebook activism that feeds the very algorithms that one may 
be aiming to resist: angry people click and clicks feed the algorithms. At a more subterranean level, practices of hacking directly into the systems that produce the algorithms may offer more critical potential, although this remains contested. As Wark, author of the hugely influential A Hacker's Manifesto (2004) has noted, hackers 'won the battle but lost the war' to the extent that 'the vectoral class' still owns the metadata and has 'regrouped around a more abstracted form of control' (Gregg and Wark, 2013, no pg).

Similar dilemmas of recuperation abound on the institutional side of the problem. For example, for all of Raunig's sensitivities to the idea that we should not presume that there are new forms of revolutionary subjectivity simply waiting in the historical wings, there is still a tendency toward a necessitarian reading of certain political struggles. He says: 'the current fields of struggle necessarily develop from the lines of flight of indigenous, ecological and feminist struggles; monopolist land ownership, extractivism, strategies of displacement and the renewed colonization of im/material commons for constituting new modes of subjectivity that no longer take recourse to the primacy of the individual' (Raunig, 2016, p. 180). While we certainly agree that such struggles offer many insights into contemporary strategies of resistance, we are more cautious about the idea that they 'necessarily' proffer forms of resistance that take flight from control. Given this caution, we would we agree with Wark to the extent that, while he refuses to praise or blame such horizontalist popular movements, he does recognize that a sole focus on their resistant potential tends toward traditional forms of 'calling to account' that are easily recuperated within institutional mechanisms of control. The conclusion he and Gregg draw from this is that we must learn how to enact our own forms of (individual and collective) 'life-hack'. 
He says; 'what if we didn't teach everyone to code but taught everyone the logic that underlies all such digital systems and gave everyone access to knowledge about how hardware and infrastructure really work? And in a way that is both abstract and practical, about systems and power, but also about how to "hack" your life? This is more promising' (our emphasis, Gregg and Wark, 2013, no pg).1

At the interface of the abstract and practical we find the means with which to challenge the snake's coils, not by appeal to an ever more fluid algorithm of movement nor by appeal to a less coiled form of institutional existence, but through the counter-sequencing of the snake's segmented movement itself. And it is at this interface that Deleuze's philosophical approach to the emergence of a new institutional form, which we have called the totalizing institution, operates most effectively as a critique of control and a series of measures by which it may be resisted both at the level of its algorithmic constitution and at the level of our dividuated existence in totalizing institutions.

\section{References}

Badiou, A. and Žižek, S. (2009) Philosophy in the Present. Cambridge: Polity.

Bratton, B. (2016) The Stack: On Software and Sovereignty. Massachusetts, MIT Press.

Bueno, C. C. (2017) The Attention Economy: Labour, Time and Power in Cognitive Capitalism. London: Rowman and Littlefield International. 
Deleuze, G. (1995) 'Postscript on Control Societies', in Negotiations: 1972-1990. New York: Columbia University Press.

Foucault, M. (1977) Discipline and Punish: The Birth of the Prison. Harmondsworth: Penguin Books.

Galloway, A. (2016) 'Protocol', Theory, Culture \& Society, No. 2-3: 317-320.

Greenfield, A. (2018) Radical Technologies: The Design of Everyday Life. London: Verso.

Gregg, M and Wark, M (2013) 'Courting Vectoralists: An Interview with McKenzie Wark on the 10 Year Anniversary of "A Hacker Manifesto", Los Angeles Review of Books, December 17.

Goffman, E. (1961) Asylums: Essays on the Social Situation of Mental Patients and Other Inmates. London: Penguin Books.

Goffman, E. (1990) The Presentation of Self in Everyday Life. London: Penguin Books.

Harman, G. (2011) The Quadruple Object. Hants.: Zero Books.

Latour, B. (2004) 'Why Has Critique Run out of Steam? From Matters of Fact to Matters of Concern', Critical Inquiry 30: 225-48. 
Lazzarato, M. (2014) Signs and Machines: Capitalism and the Production of Subjectivity. Los Angeles: Semiotext(e).

Neyland, D. and Möllers, N. (2017) 'Algorithmic IF ... THEN rules and the Conditions and Consequences of Power', Information, Communication \& Society, 20 (1): 45-62.

Raunig, G. (2016) Dividuum: Machinic Capitalism and Molecular Revolution, vol. 1. South Pasadena: Semiotext(e).

Rouvroy, A. (2012) 'The End(s) of Critique: data-behaviourism vs. due-process', in M. Hildebrandt and E. De Vries (eds.), Privacy, Due Process and the Computational Turn. Philosophers of Law Meet Philosophers of Technology. London: Routledge: 143-168.

Tarizzo, D. (2013) 'Dalla biopolitica all'etopolitica: Foucault e noi', Noema, 4: 4351.

Wark, M. (2004) A Hacker's Manifesto. Cambridge, Mass.: Harvard University Press.

Williams, J. (2016) A Process Philosophy of Signs. Edinburgh: Edinburgh University Press. 
${ }^{1}$ It is important to acknowledge here the quotidian and rather banal recuperation and domestication of the concept of 'hacking' in the last number of years in broader consumer culture. For instance, if you google 'life hacking' you are much more likely to be directed to the websites of commercial companies selling self-help and personal development strategies than to Wark's A Hacker's Manifesto. The irony of such recuperation would not be lost on a situationist like him. 